\title{
Signal overlap in the monitoring of laser welding
}

\author{
I. Eriksson, J. Powell, A.F.H. Kaplan
}

Luleå University of Technology, 97187 Luleå, Sweden

MEASUREMENT SCIENCE AND TECHNOLOGY

Meas. Sci. Technol. 21 (2010) 105705 (7pp) DOI-10.1088/0957-0233/21/10/105705

\begin{abstract}
Laser weld monitoring is usually based on the feedback from three photodiodes which are intended to provide independent information about: the thermal condition of the melt (the ' $\mathrm{T}$ ' signal), the radiation from plume of heated gas above the melt (the 'P' signal), and the amount of reflected laser light (the ' $R$ ' signal). This work demonstrates that, in fact, the plume of hot gas above the weld pool contributes a large part of the thermal signal, which has hitherto been assumed to come only from the melt itself. It is suggested that the correlation between the ' $\mathrm{T}$ ' and ' $\mathrm{P}$ ' signals is so strong that a 'T-P' signal would be more useful than the raw ' $\mathrm{T}$ ' signal in identifying the fluctuations in infra-red radiation from the melt pool.
\end{abstract}

Keywords: Laser welding, Quality control, Photodiode monitoring. 


\section{Introduction}

Although new technologies such as high speed CMOS cameras [1] and spectrometers [2] have gained some interest lately, online quality control of laser welding is still usually based on photodiodes monitoring the electromagnetic emissions from the welding process.[3-4]. It is common to use three photodiodes, each of which monitors a particular range of wavelengths - as shown in figure 1.

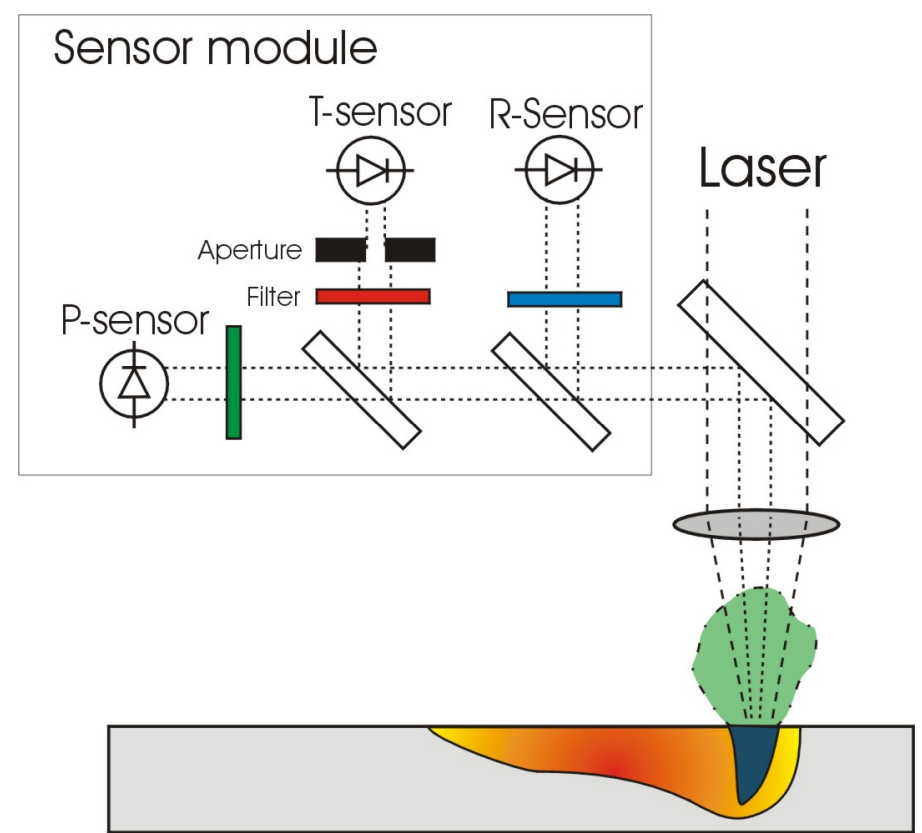

Figure 1. Three photodiodes used to monitor laser welding.

Figure 1 describes the basic design of most online monitoring systems. A $90^{\circ}$ dichromatic folding mirror deflects the electromagnetic radiation from the weld onto the sensors labelled 'P' (for 'Plasma' or 'Plume'), ' $T$ ' ('Thermal'), and ' $R$ ' ('Reflected'). The spectral range of these three sensors is shown in figure 2. The ' $T$ ' sensor monitors the infra-red emissions from the weld zone to give a measure of the average temperature in the area. The ' $\mathrm{R}$ ' sensor is designed to monitor the reflected laser light from the cut zone. The ' $\mathrm{P}$ ' sensor was originally developed for $\mathrm{CO}_{2}$ laser welding, to monitor the high temperature plasma generated when the laser ionises the vapour given off from the weld zone - this plasma ignition tends to block the passage of the laser beam and thus disrupts the welding process. When Nd:YAG lasers are used (as in this case) the laser beam does not interact with the vapour and so vapour plume temperatures are considerably lower. 


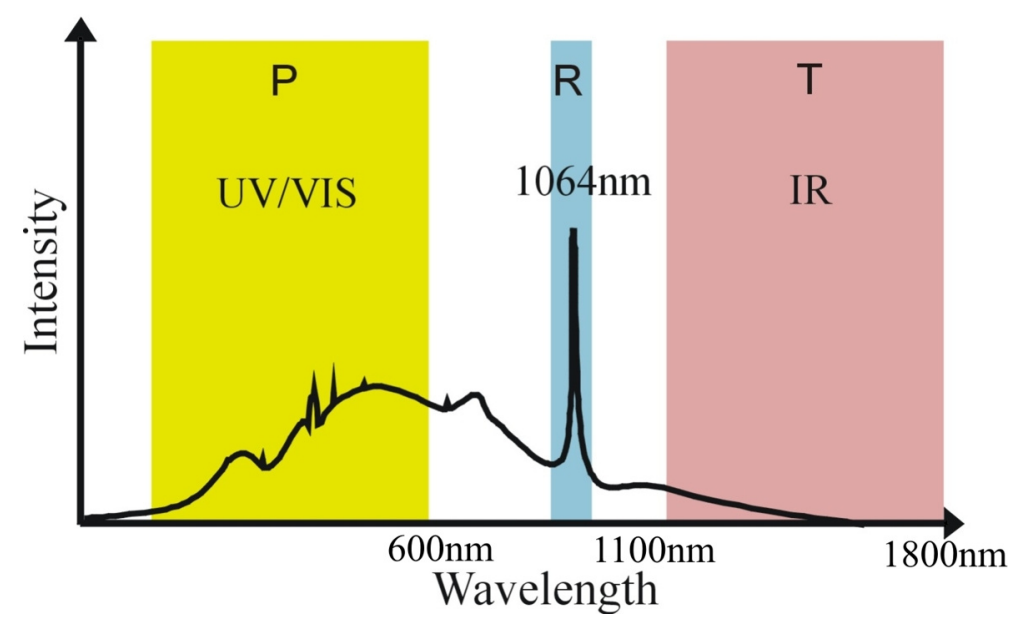

Figure 2. The spectral range of the three sensors used in Nd:YAG laser welding.

For the purposes of weld monitoring, the signals generated by the photodiodes are A/D converted and compared to a "golden template" of the signals produced during high quality welding. Excessive deviation from this 'good weld' signal will trigger an alarm, indicating that the weld quality may have changed.

The arrangement of sensors is intended to deliver three independent signals from the process, which can be used to monitor fluctuations in welding performance. The aim of this paper is to investigate the level of correlation between the three signals in order to improve our understanding of the feedback they provide, both individually and together.

\section{Experimental Work}

\subsection{Methodological approach}

The LWM (Laser Weld Monitor) system from Precitec AG was used to acquire signals of three different wavelength ranges from laser weld zones. Several different welding cases have been investigated in order to show the general nature of the results obtained.[5] High speed imaging of the welding process was used to provide additional information.

\subsection{Experimental set-up}

In this investigation, three welding situations were used as the source of the feedback signals. Titanium and zinc coated steel plates were joined in an overlap-edge welding configuration (see figure 3) using an Nd:YAG laser, and $4 \mathrm{~mm}$ thick mild steel was butt joint welded using a $\mathrm{CO}_{2}$ laser. Details of the welding cases can be found in table 1 . In the case of the Titanium welds, the material was welded in both the cleaned and uncleaned conditions in order to provide a photodiode feedback from stable and unstable weld pools. Similarly, the Zinc coated steel welds were carried out with three different levels of weld fit-up or misalignment in order to provide signals from welds with three different levels of stability.

Table 1. Details of the welding parameters.

\begin{tabular}{llllllll}
\hline $\begin{array}{l}\text { Joint } \\
\text { Type }\end{array}$ & Laser & Material & Thickness & Power & $\begin{array}{l}\text { Welding } \\
\text { speed }\end{array}$ & $\begin{array}{l}\text { Shielding } \\
\text { gas }\end{array}$ & $\begin{array}{l}\text { Weld } \\
\text { quality }\end{array}$ \\
\hline Overlap & Nd:YAG & Titanium & $2 \times 0.6 \mathrm{~mm}$ & $2 \mathrm{~kW}$ & $5 \mathrm{~m} / \mathrm{min}$ & Argon & High \\
Overlap & Nd:YAG & Titanium & $2 \times 0.6 \mathrm{~mm}$ & $2 \mathrm{~kW}$ & $5 \mathrm{~m} / \mathrm{min}$ & Argon & Moderate
\end{tabular}


Signal overlap in the monitoring of laser welding

$\begin{array}{llllllll}\text { Lap } & \text { Nd:YAG } & \begin{array}{c}\text { Zn-coated } \\ \text { Steel }\end{array} & 2 \times 0.8 \mathrm{~mm} & 2.5 \mathrm{~kW} & 6 \mathrm{~m} / \mathrm{min} & \text { Argon } & \text { High } \\ \text { Lap } & \text { Nd:YAG } & \begin{array}{c}\text { Zn-coated } \\ \text { Steel }\end{array} & 2 \times 0.8 \mathrm{~mm} & 2.5 \mathrm{~kW} & 6 \mathrm{~m} / \mathrm{min} & \text { Argon } & \text { Moderate } \\ \text { Lap } & \text { Nd:YAG } & \begin{array}{c}\text { Zn-coated } \\ \text { Steel }\end{array} & 2 \times 0.8 \mathrm{~mm} & 2.5 \mathrm{~kW} & 6 \mathrm{~m} / \mathrm{min} & \text { Argon } & \text { Low } \\ \text { Butt } & \mathrm{CO}_{2} & \begin{array}{c}\text { Mild Steel } \\ \text { Milm }\end{array} & 2.5 \mathrm{~kW} & 2 \mathrm{~m} / \mathrm{min} & \text { Helium } & \text { High }\end{array}$

The Nd:YAG laser welds were monitored with coaxial sensors, as shown in figure 1 . For the $\mathrm{CO}_{2}$ laser an external off axis sensor setup (mounted as close to the focusing lens as possible) was employed, as a coaxially mounted scraper mirror was incompatible with our laser setup. During the $\mathrm{CO}_{2}$ laser welding, only the T-sensor and P-sensor were used because silicon photodiodes and dichromatic mirrors do not work at the $10.6 \mu \mathrm{m}$ wavelength of $\mathrm{CO}_{2}$ laser. The maximum resolution and sampling speed of the system (8-bit and $20 \mathrm{kHz}$ signal) was utilized to provide the highest level of detail for signal comparison.

The T-sensor was employed without an aperture in order to maximise the area monitored. This makes it possible to compare signal responses in different welding cases, with different materials, welding power and welding speed. The aperture is normally used to concentrate on an area to the rear of the melt pool, away from the effects of the keyhole and weld plume. The use of an aperture can help in reducing the noise in the signal, but the setup becomes extremely sensitive to misalignment.

\subsection{High speed video imaging and plume monitoring}

As the initial trials revealed a high correlation between the P-sensor and T-sensor signals, the vapour plume above the weld was monitored by high speed imaging and compared with the three photodiode signals. A Photron SA1 camera running at 40000fps was used to film the plume from behind - see figure 3 .

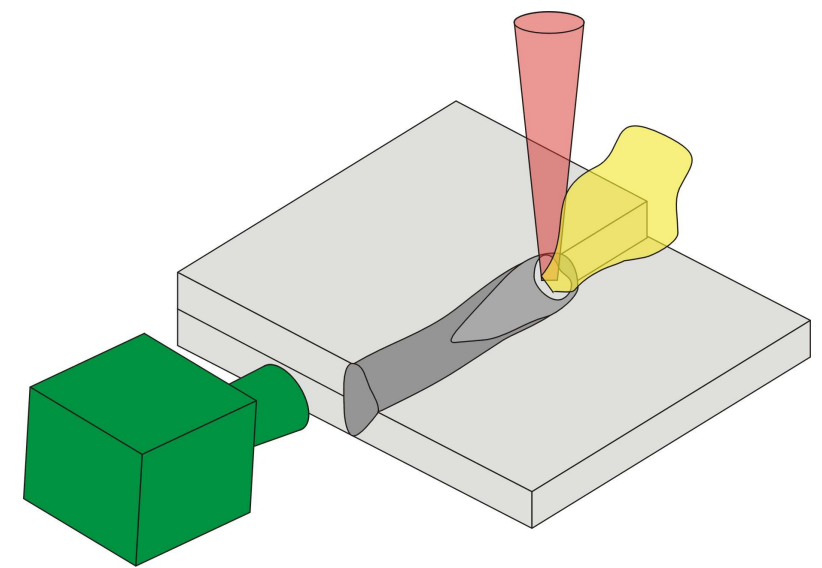

Figure 3 Camera setup for plume monitoring during overlap-edge welding.

The camera was inclined at approximately 5 degrees to the horizontal and the focus and exposure time were adjusted to monitor the image of the plume ejected from the keyhole - see figure 4 . This arrangement provided an independent signal source which only monitored the plume. The camera employed a protective filter to block out the intense laser light at $1064 \mathrm{~nm}$. The wavelength sensitivity of the camera was similar to that of the P-sensor as they were both based on silicon semiconductors. The spectral response of the entire optical setup can be assumed to be a broadband sensitivity of $\sim 400$ $800 \mathrm{~nm}$. 


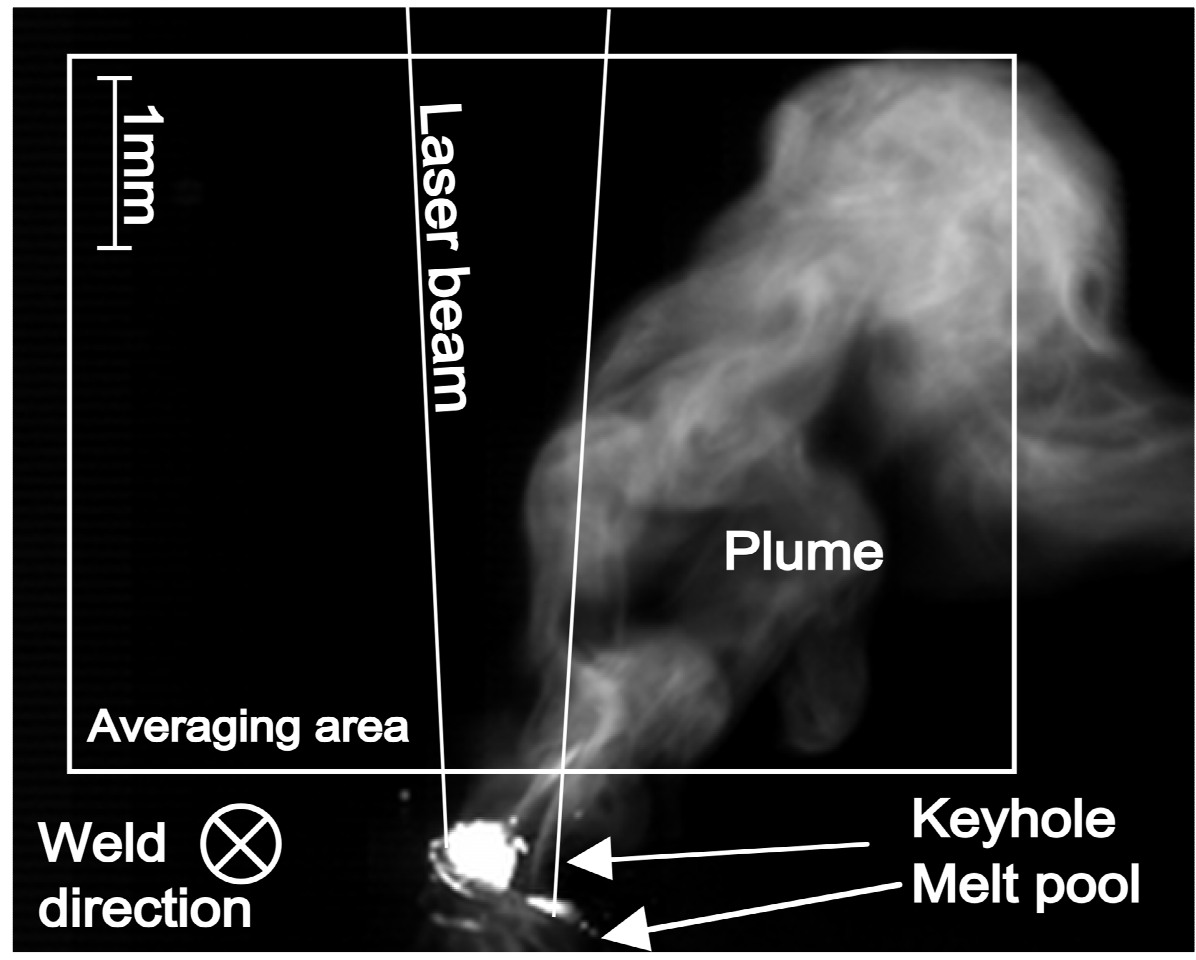

Figure 4. A typical single video frame of the vapour plume.

\subsection{Statistical method for evaluating the correlation between signals}

The correlation between the photodiode signals was quantified by the Pearson correlation coefficient ( $\rho$ ) described in Equation 1 [6]. The expected value $(E)$ of the signal deviation from its mean $(\mu)$ is divided by the standard deviations $(\sigma)$ of the signals. The Pearson correlation is a measurement of how well a linear equation can represent the measured values of two variables. The value of the correlation ranges from -1 to +1 , where 0 indicates totally independent signals. A higher absolute number shows a stronger correlation of the signals.

$$
\rho_{X, Y}=\frac{E\left(\left(X-\mu_{X}\right)\left(Y-\mu_{Y}\right)\right)}{\sigma_{X} \sigma_{Y}}
$$

A high (close to +1$)$ correlation value between two signals generally indicates that there is a linear dependence of the signals. [7].

\section{Results}

\subsection{Typical photodiode signal appearance}

Sensor signals differ for different welding parameters. The amplitude and the frequency content changes, but some characteristics are usually similar. These are:

- A short ( 1ms) peak in the R-signal during the creation of the keyhole. This phenomenon is often accompanied by peaks in the $\mathrm{P}$ and $\mathrm{T}$ sensors signals (see figure 5)

- A period of fluctuations until the melt pool is stable (See figure 5). The extent of this phenomenon is highly dependent on welding speed.

- A high level of high frequency noise in the $\mathrm{T}$ and $\mathrm{P}$ signals during keyhole welding (see figure 6)

- An $\mathrm{e}^{-\mathrm{t} / \tau}$ type curve for the T-sensor at the end of the weld. 


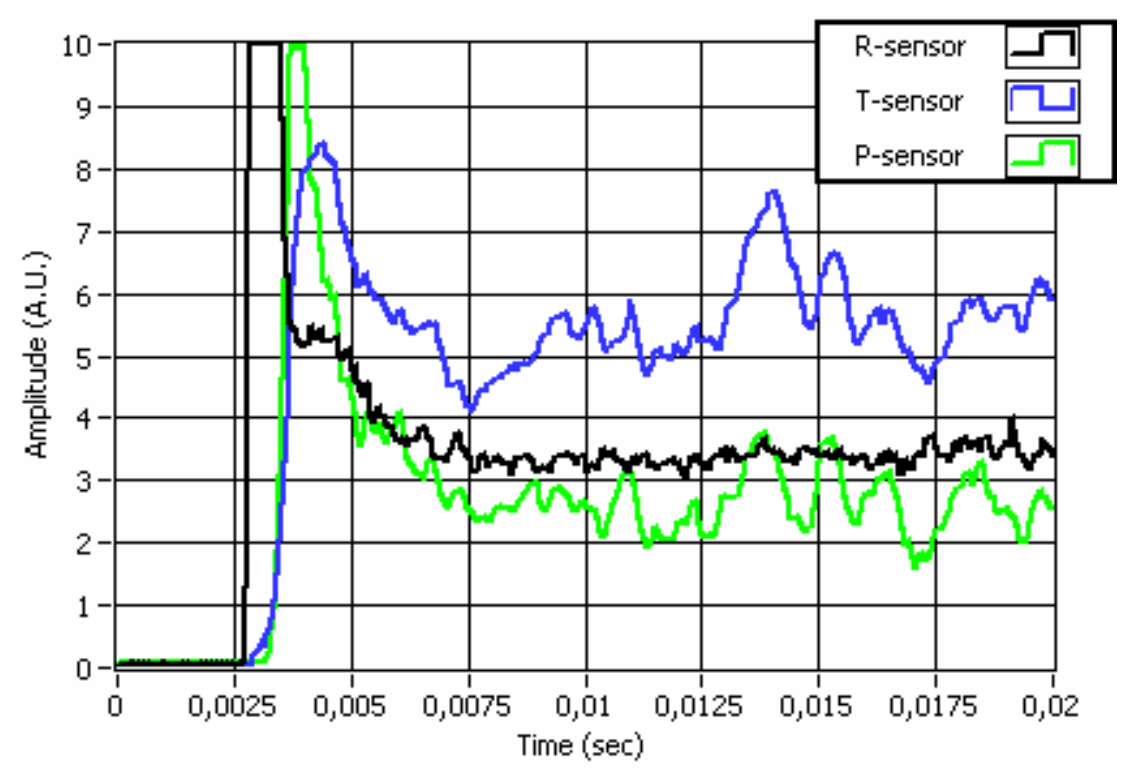

Figure 5. Weld start-up behaviour

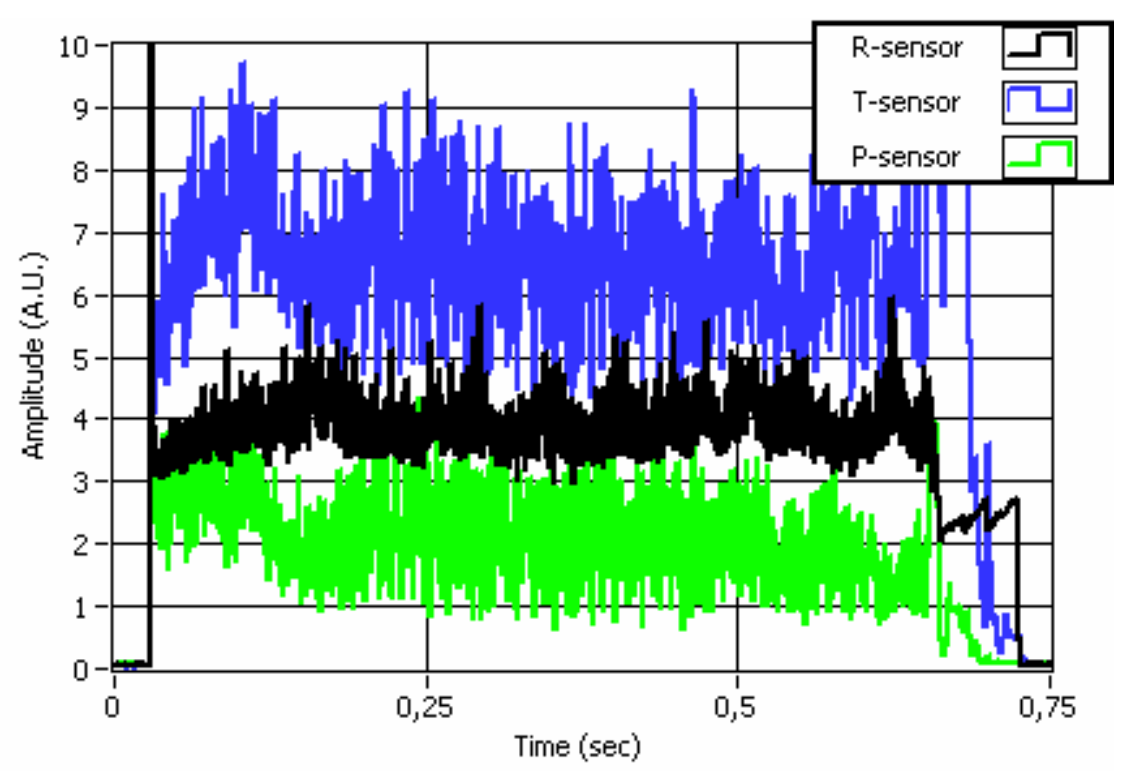

Figure 6. The entire signal set from the high quality titanium weld.

Previous workers [8] have generally concentrated on the fluctuations of the signal curves which are in the tens or hundreds of Hertz. In this paper an analysis of the correlation between the signals at higher frequencies was carried out which revealed an interesting link between the $\mathrm{T}$ and $\mathrm{P}$ signals.

\subsection{Correlations between the sensors}

Figure 7 presents a close up view of some of the information provided in figure 6 . At this level of detail it is clear that there is considerable correlation between the $\mathrm{T}$ and $\mathrm{P}$ photodiode signals. This suggests that the signals might emanate from the same source. 


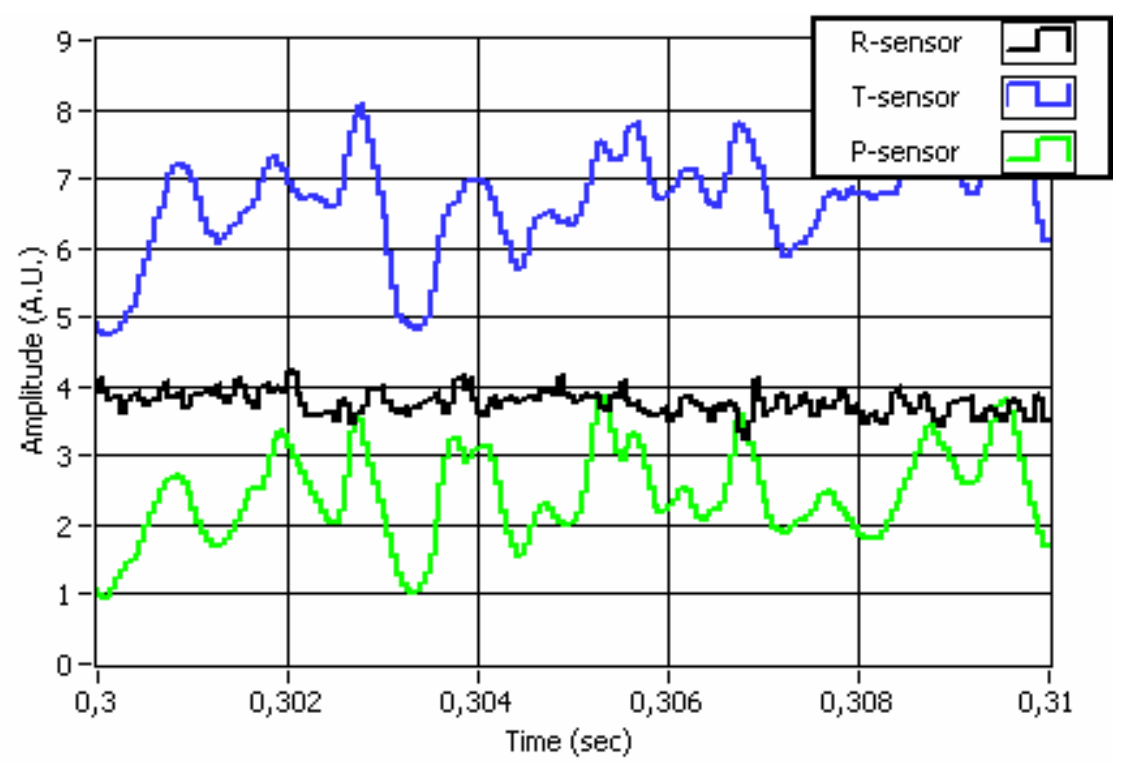

Figure 7. The high frequency noise/signal correlation.

To quantify the relationship between the two signals, 10000 samples from each signal were collected and the Pearson correlation, mean value and variance were calculated for the 6 different types of weld. This information is presented in table 2.

Table 2. Calculated correlation values from 10000 samples of weld signal in each case.

\begin{tabular}{|c|c|c|c|c|c|c|}
\hline \multicolumn{2}{|c|}{ Weld Type } & $\begin{array}{l}\text { T-P Pearson } \\
\text { Correlation }\end{array}$ & $\begin{array}{l}\text { T-R } \\
\text { Pearson } \\
\text { Correlation }\end{array}$ & $\begin{array}{l}\text { T-mean } \\
\text { (a.u.) }\end{array}$ & $\begin{array}{l}\text { T- } \sigma \\
\text { (a.u.) }\end{array}$ & $\begin{array}{l}\text { P-mean } \\
\text { (a.u.) }\end{array}$ \\
\hline \multirow[t]{2}{*}{ Titanium } & Stable & 0,79 & $-0,05$ & 6,4 & 0,83 & 2,0 \\
\hline & Unstable & 0,75 & $-0,04$ & 6,5 & 0,99 & 2,0 \\
\hline Zn-coated & Stable & 0,93 & 0,27 & 1,8 & 0,31 & 1,4 \\
\hline \multirow[t]{2}{*}{ Steel } & Intermediate & 0,80 & 0,08 & 2,8 & 0,31 & 2,0 \\
\hline & Unstable & 0,93 & 0,50 & 2,6 & 0,45 & 2,1 \\
\hline $\mathrm{CO}_{2}$ laser & Steel & 0,78 & & 0,84 & 0,10 & 0,65 \\
\hline
\end{tabular}

From the information given in table 2, it is clear that there is a high level of correlation between the $T$ and $\mathrm{P}$ signals under all these welding conditions. It is worth noting at this point that the vapour plume in the case of the $\mathrm{CO}_{2}$ laser weld was prevented from becoming over heated and ionised by the use of Helium as a shielding gas.

\subsection{Plume activity}

The high speed camera photographs below were taken of the vapour plume from the Stable Zinccoated steel weld. It is clear that the size and brightness of the plume fluctuates rapidly - these photographs represent a time interval of only 75 microseconds. The fluctuations in the light emitted by the plume were monitored by analysing each video frame using 'Labview' software to calculate the average image intensity over the total viewed area (outlined in figure 4).
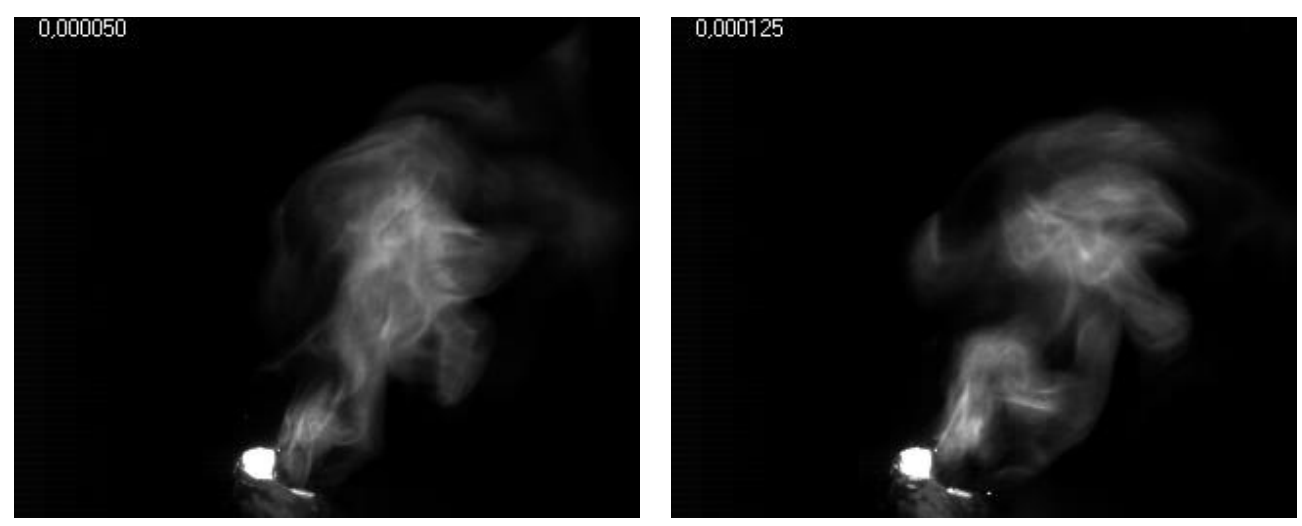
Signal overlap in the monitoring of laser welding

Figure 8. High speed video still photographs of plume activity (photographs are 75 microseconds apart).

In figure 9 the $\mathrm{T}$ and $\mathrm{P}$ signal values and average image intensity are plotted as a function of time. The peaks are clearly correlated and most of the variation can be correlated to plume intensity. The Pearson correlation calculated for this part of this weld was 0,92 for T-sensor/P-sensor. And the Psensor correlation to the average image intensity was 0,90 .

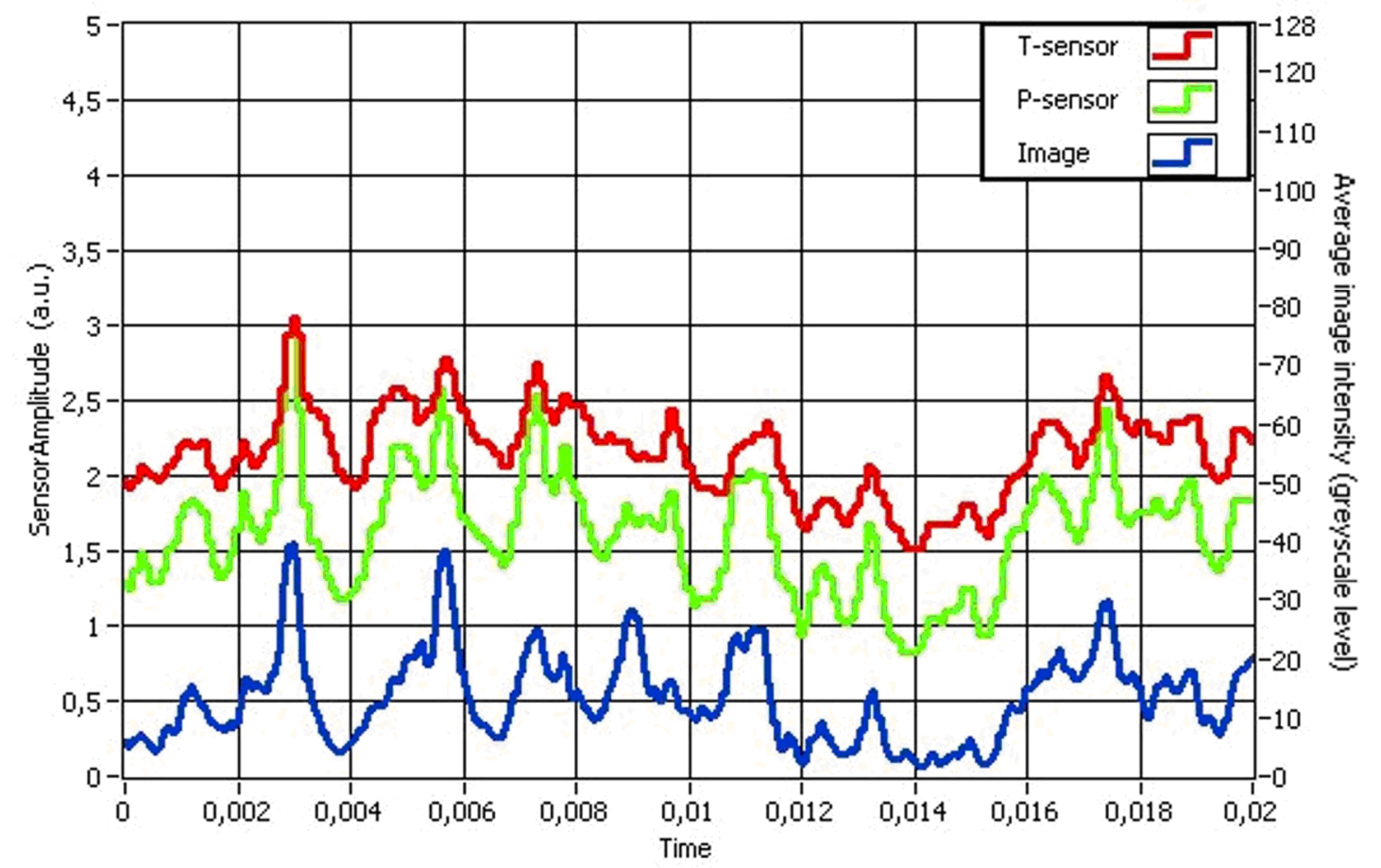

Figure 9. Correlation between P- and T-photodiode signals and plume image intensity.

Figure 9 gives a strong indication that the electromagnetic radiation from the plume is a major contributor to the signal generated by the $\mathrm{T}$ sensor.

\subsection{Identification of the plume radiation characteristics}

One question is; Is the plume above the keyhole generating light or merely reflecting the light from the keyhole? To test this, a shadowing rod was inserted into the plume. In this experiment an overlap weld in Zinc coated steel was carried out. The rod was placed normal to the camera view as shown in figure 10. This rod was attached to the welding head and therefore followed the welding process at a set distance of $1.5 \mathrm{~mm}$. 

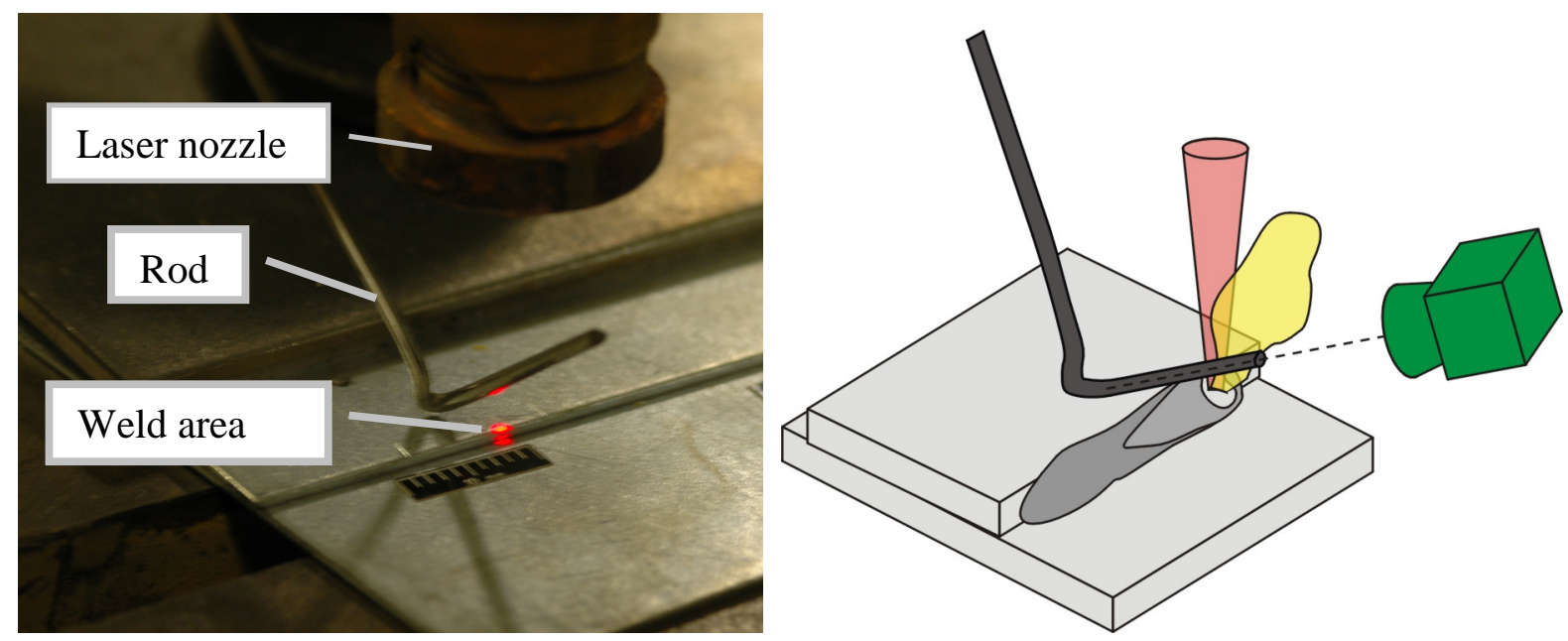

Figure 10. The arrangement of the shadow-casting rod and camera.

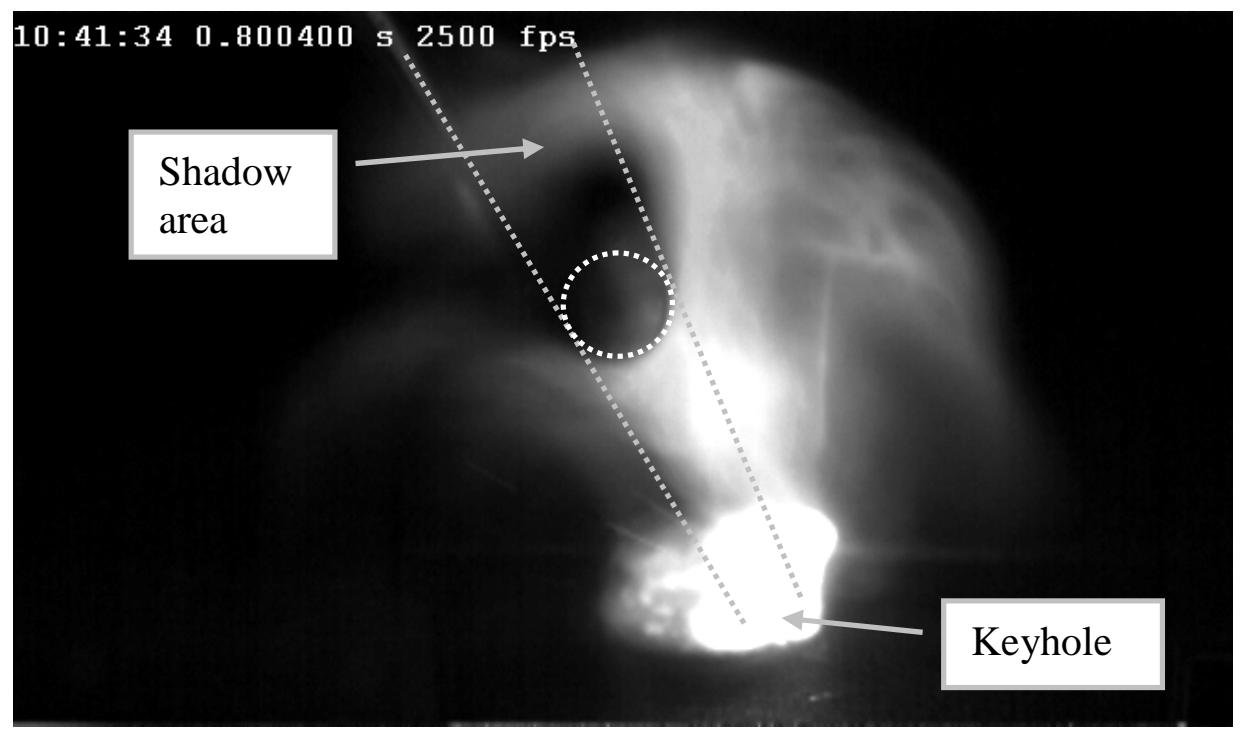

Figure 11. Plume generating light even in rod-shadowed area.

In figure 11 it is visible that the plume is glowing in the area shadowed by the rod where no light from the keyhole can reach it. This means that the plume is emitting rather than reflecting light. If this plume radiation could be subtracted from the signals, the noise contribution from the plume would be eliminated and more accurate measurements could be made of the fluctuations in the radiated output from the melt.

\section{Discussion}

Earlier work by a number of authors $[9,10]$ has generally assumed that the signals from the three sensors have not included a great deal of overlap, and that the $\mathrm{T}$ (Infra-red, thermal) signal emanated primarily from the surface of the melt pool. The fluctuations in this signal have generally been attributed to noise.

The results shown above reveal that, rather than radiating solely at Ultra-Violet and Visible wavelengths, the vapour plume actually radiates as a black body over a wide range of wavelengths 
including the Infra-Red. Wien's displacement law tells us that the majority of the radiation of the hot plume will be at shorter wavelengths (which will be monitored by the P sensor) - but this shorter wavelength radiation will be accompanied by infra-red output (which will be picked up by the $T$ sensor). This means that the 'noise' of the T signal is, in fact a direct measure of the fluctuation in emission of the plume as a result of changes in its size (a larger plume emits more light) and temperature. As the plume and weld pool is of different temperature the emission proportion will change in different wavelength areas, this gives the possibility to do a signal separation of the signals in the T-sensor and P-sensor.

Figure 12 demonstrates the point that we get a clearer view of the variation of the weld pool generated IR signal if we subtract the ' $\mathrm{P}$ ' signal from the ' $\mathrm{T}$ ' signal. In the absence of the 'noise' from the ' $\mathrm{P}$ ' signal, the ' $\mathrm{T}$ ' signal is considerably less prone to fluctuation. This level of fluctuation is more in keeping with emission of infra-red light from a molten liquid surface than the large, high frequency fluctuations noted in the raw ' $\mathrm{T}$ ' signal.

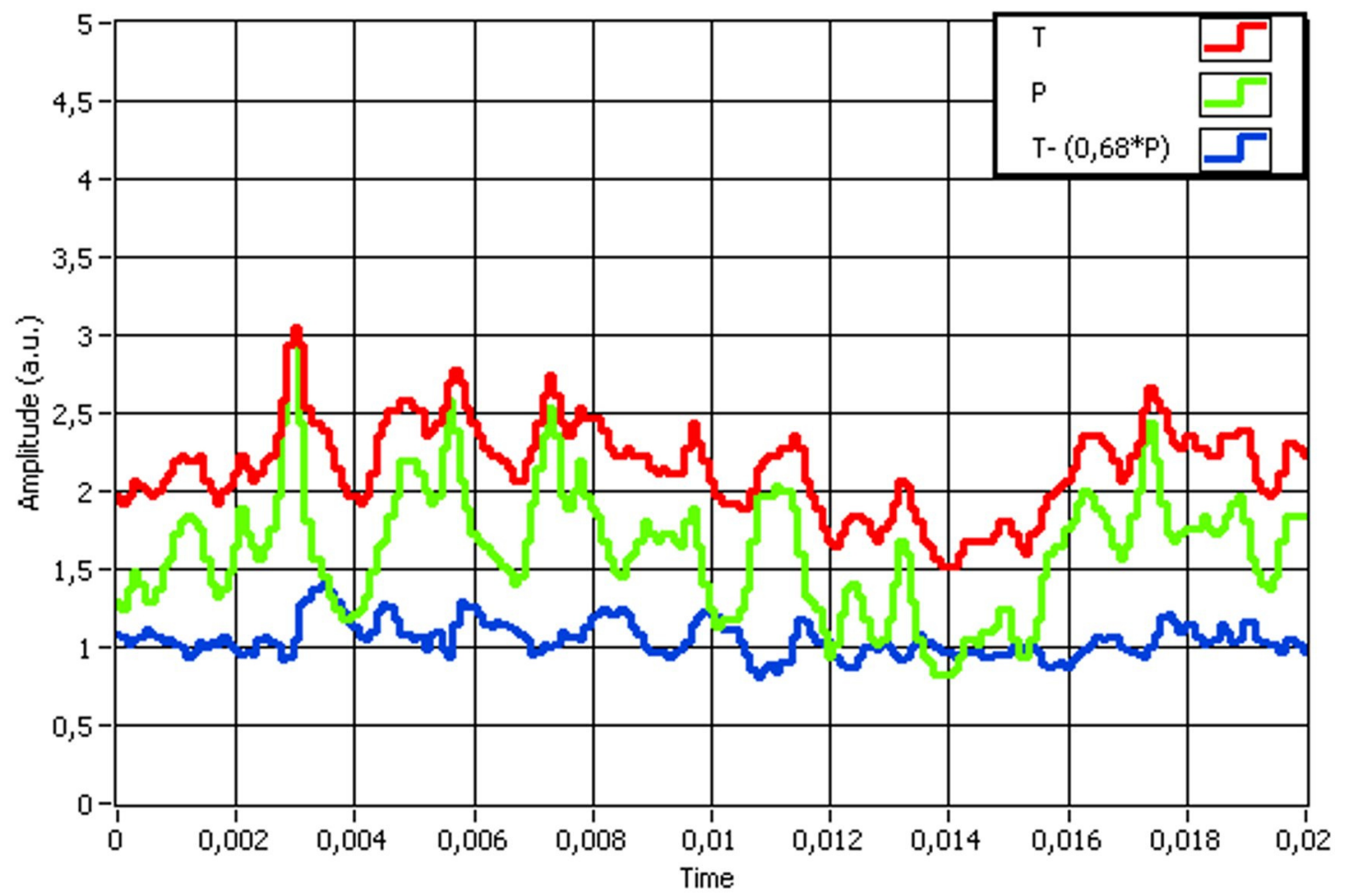

Figure 12. The relatively low variance of the IR emissions from the melt surface and the surrounding heated substrate is clear if the $\mathrm{P}$ signal is removed from the T signal. (The P signal has been scaled to match the peak height of the T signal).

The plume originates from the walls of the keyhole as a very hot gas which, as it exits the keyhole, will emit electromagnetic energy in the ultra-violet and visible ranges. However, it is clear from these results that the plume which is visible above the weld zone emits a substantial proportion of infra-red light. This infra-red radiation is picked up by the Thermal sensor which is intended to monitor only the condition of the melt and the surrounding heated solid. The plume of cooling gas can, to a first approximation, be considered a black body radiator over a wide spectrum. The amount of energy it radiates is related to the volume of the vapour plume, which fluctuates rapidly.

It is clear from this work that a more accurate measure of the thermal condition of the melt pool can be obtained if the ' $\mathrm{P}$ ' signal is removed from the ' $\mathrm{T}$ ' sensor signal. This simple remedy would reduce the amount of signal noise which exists in the present system. A more advanced signal separation 
technique than a simple subtraction would enable even more reliable process monitoring. By using more then two wavelength areas and suitable signal separation this could become a promising method to monitor fluctuations in the melt pool, which are closely related to the final weld quality.

\section{Conclusions}

This work has demonstrated that;

- The plume of gas visible above the laser weld pool emits a broad band of electromagnetic radiation including a substantial amount of infra-red.

- The level of radiation emitted by the plume is related to the plume volume, which fluctuates rapidly.

- The infra-red radiation from the plume is picked up by the $\mathrm{T}$ sensor and this makes the $\mathrm{T}$ sensor far less useful as a method of measuring the thermal condition of the melt pool.

- A more accurate measure of the fluctuations in the melt condition (which are related to fluctuations in the IR emission from the melt) could be achieved by subtracting the 'P' signal from the ' $T$ ' signal.

\section{Acknowledgements}

This work was founded by VINNOVA as a part of the DATLAS project. The authors are also grateful to Per Gren at Luleå University of Technology and Precitec AG.

\section{References}

[1] F Bardin, A Cobo, J Lopez-Higuera, O Collin, P Aubry, T Dubois, M Högström, P Nylen, P Jonsson, J Jones and D Hand 2005 Closed-loop power and focus control of laser welding for full-penetration monitoring Appl. Opt. 44 p 3869-76

[2] T Sibillano, A Ancona, V Berardi and PM Lugara 2005 Correlation analysis in laser welding plasma Opt. Comm. 251 p139-48

[3] P Norman, H Engström and A Kaplan 2007 State-of-the-art of monitoring and imaging of laser welding defects 11th NOLAMP Conference in Laser Processing of Materials

[4] J Shao and Y Yan, 2005 Review of techniques for on-line monitoring and inspection of laser welding, J. Phys. Conf. Ser. 15 p 101-7

[5] I Eriksson, and A Kaplan 2009 Evaluation of laser weld monitoring - A case study, ICALEO

[6] Joseph Lee Rodgers and W. Alan Nicewander 1988.Thirteen Ways to Look at the Correlation Coefficient ,The American Statistician, 42 p 59-66

[7] A E Castro Sotos, S Vanhoof, W Van den Noortgate and P Onghena 2007 The Non-Transitivity of Pearson's Correlation Coefficient: An Educational Perspective, International Statistical Institute, 56th Session 
Signal overlap in the monitoring of laser welding

[8] M Geiger, C Kägeler, M Schmidt 2008 High-power laser welding of contaminated steel sheets, Prod.Eng. Devel. 2 p235-40

[9] P Norman, H Engström, P Gren and A Kaplan. 2008 Correlation between photodiode monitoring and high speed imaging of the dynamics causing laser welding defects, ICALEO. p 829-837

[10] J Ortmann, E W Kreutz, C Maier, T Wehner, M Kogel-Hollacher, S Kaierle, R Poprawe 2003 Online Detection of Defect Classes for Laser Beam Welding ICALEO p C56-62 